\title{
Fetoplacental growth and vascular development in overnourished adolescent sheep at day 50,90 and 130 of gestation
}

\author{
Dale A Redmer ${ }^{2}$, Justin S Luther ${ }^{1,2}$, John S Milne ${ }^{1}$, Raymond P Aitken ${ }^{1}$, Mary Lynn Johnson ${ }^{2}$, \\ Pawel P Borowicz ${ }^{2}$, Magda A Borowicz ${ }^{2}$, Lawrence P Reynolds ${ }^{2}$ and Jacqueline M Wallace ${ }^{1}$ \\ ${ }^{1}$ Rowett Institute of Nutrition and Health, University of Aberdeen, Aberdeen AB21 9SB, UK and ${ }^{2}$ Department of \\ Animal Sciences, Center for Nutrition and Pregnancy, North Dakota State University, Fargo, North Dakota
} 58105, USA

Correspondence should be addressed to J M Wallace; Email: jacqueline.wallace@rowett.ac.uk

\begin{abstract}
To establish the basis for altered placental development and function previously observed at late gestation, fetoplacental growth and placental vascular development were measured at three stages of gestation in a nutritional paradigm of compromised pregnancy. Singleton pregnancies to a single sire were established and thereafter adolescent ewes were offered an optimal control $(\mathrm{C})$ or a high $(\mathrm{H})$ dietary intake. At day 50, the $\mathrm{H}$ group had elevated maternal insulin and amniotic glucose, whereas mass of the fetus and placenta were unaltered. At day 90, the $\mathrm{H}$ group exhibited elevated maternal insulin, IGF1 and glucose; fetal weight and glucose concentrations in $\mathrm{H}$ were increased relative to $C$, but placental weight was independent of nutrition. By day 130 , total placentome weight in the $H$ group was reduced by $46 \%$ and was associated with lower fetal glucose and a $20 \%$ reduction in fetal weight. As pregnancy progressed from day 50 to 130, the parameters of vascular development in the maternal and fetal components of the placenta increased. In the fetal cotyledon, high dietary intakes were associated with impaired vascular development at day $\mathbf{5 0}$ and an increase in capillary number at day $\mathbf{9 0}$. At day 130, all vascular indices were independent of nutrition. Thus, high dietary intakes to promote rapid maternal growth influence capillary development in the fetal portion of the placenta during early to mid-pregnancy and may underlie the subsequent reduction in placental mass and hence fetal nutrient supply observed during the final third of gestation.
\end{abstract}

Reproduction (2009) 137 749-757

\section{Introduction}

Pregnancy in adolescent women is characterized by an increased risk of miscarriage, prenatal growth restriction, and preterm birth (Scholl et al. 1994, Olausson et al. 1999; http://www.marchofdimes.com/professionals/ 14332_1159.asp). These negative pregnancy outcomes are most prevalent in very young girls who have yet to complete their own body growth (reviewed in Wallace et al. 2006a). Indeed, data from the Camden Adolescent Pregnancy and Nutrition Project (Scholl et al. 1997) suggests that continued maternal growth occurs in $\sim 50 \%$ of adolescents and, in spite of larger pregnancy weight gains and increased fat stores, is associated with a modest but significant reduction in birth weight compared with non-growing adolescent mothers. This effect is attributed to a competition for nutrients between the maternal body and her gravid uterus, which is unique to the adolescent growth period and has been replicated in our ovine model.

Thus, we have repeatedly demonstrated that overnourishing the singleton-bearing adolescent ewe promotes rapid maternal growth at the expense of the gravid uterus. This results in the premature delivery of low birth weight lambs following spontaneous delivery close to term (Wallace et al. 1996, 2001, 2004a). Inadequate placental development is central to these negative outcomes and by late gestation placental mass is typically reduced by $30-40 \%$ and is associated with a corresponding reduction in both uterine and umbilical blood flows (Wallace et al. 2002a). This directly impacts transplacental transport of nutrients to the fetus, and hence absolute umbilical uptakes of glucose, oxygen and amino acids are attenuated, leading to a slowing of fetal growth in the final third of gestation (Wallace et al. $2002 a, 2002 b, 2003 b$ ). We originally hypothesized that these late pregnancy events are preceded and mediated by alterations in placental angiogenesis and vascular development, and, indeed, we demonstrated attenuated expression of mRNA for a number of angiogenic factors and their receptors in whole placentomes collected at mid-gestation from overnourished dams (Redmer et al. 2005). This is not surprising, as placental angiogenesis is 
critical to the exponential increase in uterine blood flows seen throughout pregnancy (Reynolds \& Redmer 1995) and is variously altered in each of the several models of compromised pregnancy in sheep (Reynolds et al. 2006). However, an important limitation of most of the previous studies is that changes in utero-placental growth, vascular development, and function were evaluated only at a single stage of pregnancy, usually near term (Reynolds et al. 2006).

The aim of this study was to utilize placental perfusion techniques and image analyses to quantify placental vascular development in both the maternal and fetal components of the placenta in putatively growthrestricted compared with normally developing pregnancies at three physiologically significant stages of gestation. In the sheep, these stages are known to coincide with rapid placental cellular proliferation (day 50; Ehrhardt \& Bell 1995), exponential vascular development of the fetal cotyledon (day 90; Reynolds et al. 2005) and maximized placental vascularization, blood flow, and nutrient transfer functions (day 130; Bell et al. 1987, Reynolds et al. 2005). Furthermore, maternal and fetal organ growth, endocrinology, and metabolic status were determined at the three stages of gestation studied and related to the measured placental parameters.

\section{Results}

\section{Maternal body weight and body condition changes}

Weekly changes in maternal body weight and body condition are presented in Fig. 1. By approximately day 35 of gestation, maternal body weight and body condition score were elevated $(P<0.001)$ in the $\mathrm{H}$ versus the $C$ groups and the relative difference between
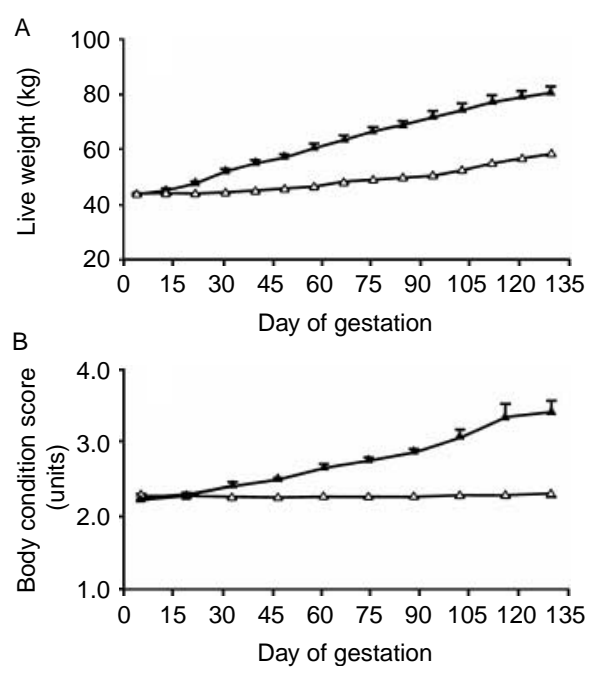

Figure 1 Weekly maternal body weight (A) and body condition score (B) changes throughout gestation in control $(\triangle)$ and high $(\boldsymbol{\Delta})$ intake adolescent dams (B). Values are means \pm S.E.M. these groups increased as gestation advanced. Maternal body condition was maintained from embryo transfer to necropsy in all ewes in the $C$ group, as per the experimental design.

\section{Maternal and fetal metabolic status at necropsy}

Maternal and fetal growth and metabolic status at necropsy is presented in Table 1. Compared with the C group, maternal body weight, which is the combined weight of the maternal carcass, blood, internal organs, empty alimentary tract and fat depots, was greater in the $\mathrm{H}$-intake adolescent dams at all stages. Furthermore, $\mathrm{H}$ dietary intakes significantly elevated absolute perirenal fat at all necropsy stages compared with the $C$ group, and increased liver weight regardless of stage of gestation. Although maternal pancreas weight was lower in $\mathrm{C}$ dams at the early necropsy stage (day 50), it was similar to $\mathrm{H}$ dams at days 90 and 130 .

Concentrations of key anabolic hormones were elevated in $\mathrm{H}$ dams. In particular, maternal insulin concentrations were substantially greater across all stages of gestation compared with the $\mathrm{C}$ group (Table 1). Likewise, maternal plasma IGF1 concentrations were greater in $\mathrm{H}$ than $\mathrm{C}$ across all stages of gestation and generally increased across stage, whereas plasma glucose concentrations were significantly greater in $\mathrm{H}$ than $\mathrm{C}$ but were similar across stage. By contrast, maternal progesterone concentrations in the rapidly growing $(\mathrm{H})$ dams were reduced $(P<0.001)$ during the final two-thirds of gestation.

As shown in Table 1, at day 90 of gestation, fetal weight was greater in $\mathrm{H}$ versus $\mathrm{C}$ groups, but as gestation advanced to day 130 , fetal growth in the $\mathrm{H}$ group slowed substantially and fetal weight was reduced significantly, being $20 \%$ less than the $\mathrm{C}$ group. The increased fetal weight in the $\mathrm{H}$ versus $\mathrm{C}$ group at day 90 of gestation was associated with an increase in fetal brain weight; however, at day 130 of gestation absolute perirenal fat, brain, pancreas, and liver weights were not significantly different between groups. Although the stage $\times$ nutrition interaction was weak $(P<0.07)$, at day 130 the brain:fetal weight ratio was significantly greater in the growth-restricted fetuses of the $\mathrm{H}$ dams $(P<0.008)$ relative to normally growing $C$ fetuses, commensurate with fetal brain-sparing.

The observed differences in fetal weight mirrored the differences in amniotic and/or fetal plasma glucose concentrations. At day 50 of gestation, amniotic glucose concentrations were elevated in the $\mathrm{H}$ versus the $\mathrm{C}$ group. As gestation advanced to day 90, amniotic glucose concentrations increased further and paralleled the greater fetal plasma glucose concentrations in the $\mathrm{H}$ group at this stage compared with the $\mathrm{C}$ group. By contrast, in late gestation (day 130) fetal growth restriction in the $\mathrm{H}$ versus the $\mathrm{C}$ group was associated with a reduction in amniotic and fetal plasma glucose 


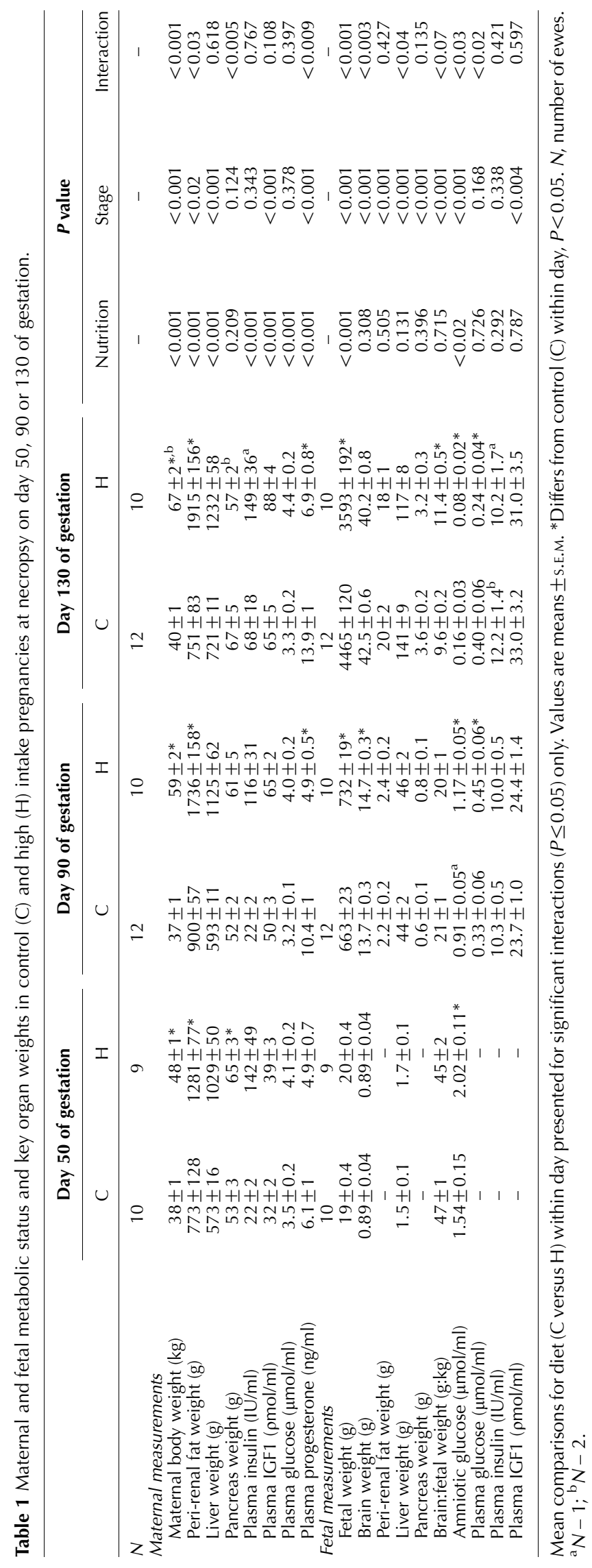

concentrations. Fetal plasma insulin and IGF1 concentrations at both day 90 and 130 were highly variable and were unaffected by maternal diet.

\section{Placental growth and vascular development}

Changes in placental growth and vascular development resulting from maternal dietary treatment and stage of gestation are presented in Table 2. Gravid uterine weight and combined amniotic and allantoic fluid volume remained similar between dietary groups up to day 90 of gestation, but declined in the $\mathrm{H}$ versus the $\mathrm{C}$ group by day 130 , resulting in a significant interaction between stage of gestation and maternal nutrition. Total and mean placentome weights in the $\mathrm{H}$ group were significantly reduced compared with the $\mathrm{C}$ group, but predominantly during late gestation, also resulting in a significant stage $\times$ nutrition interaction. At day 130 of gestation, this represented a reduction in total and mean placentome weight of 46 and $41 \%$ respectively, in the $\mathrm{H}$ relative to the $\mathrm{C}$ group $(P<0.01)$. Placentome number was not influenced by maternal diet or stage of gestation. The fetal:placentome weight ratio increased as gestation advanced in both treatment groups and was greater in $\mathrm{H}$ compared with $\mathrm{C}$ beginning on day 90 . Overall, cellular proliferation of the fetal cotyledon tended $(P=0.072)$ to be less in $\mathrm{H}$ versus $\mathrm{C}$ (Table 2) and decreased across gestation.

Over all stages of gestation, cotyledonary capillary surface density was greater in $\mathrm{H}$ compared with $\mathrm{C}$ and increased in both groups across gestation (Table 2). At day 50 of gestation, area per capillary and capillary area density was reduced in the fetal cotyledon of $\mathrm{H}$ compared with C fetuses (Table 2). These early reductions in cotyledonary capillary area density and area per capillary are readily observed (see micrographs, Fig. 2) and led to significant interactions between maternal dietary intake and stage of gestation (Table 2). As gestation advanced to day 90, cotyledonary capillary number density in the $\mathrm{H}$ group (Table 2) increased compared with controls. As gestation advanced to day 130, cotyledonary capillary surface, area, and number densities increased irrespective of diet, whereas area per capillary in the fetal cotyledon declined.

Proliferative growth in the maternal caruncle was not significantly altered by diet, but this parameter did remain numerically lower at all stages of gestation in $\mathrm{H}$ versus C (Table 2). As gestation advanced, maternal caruncular cellular proliferation declined. None of the vascularity parameters in the maternal caruncle were altered by diet. However, similar to the fetal cotyledon, capillary surface density, capillary area density and capillary number density increased as gestation advanced, whereas area per capillary declined. 


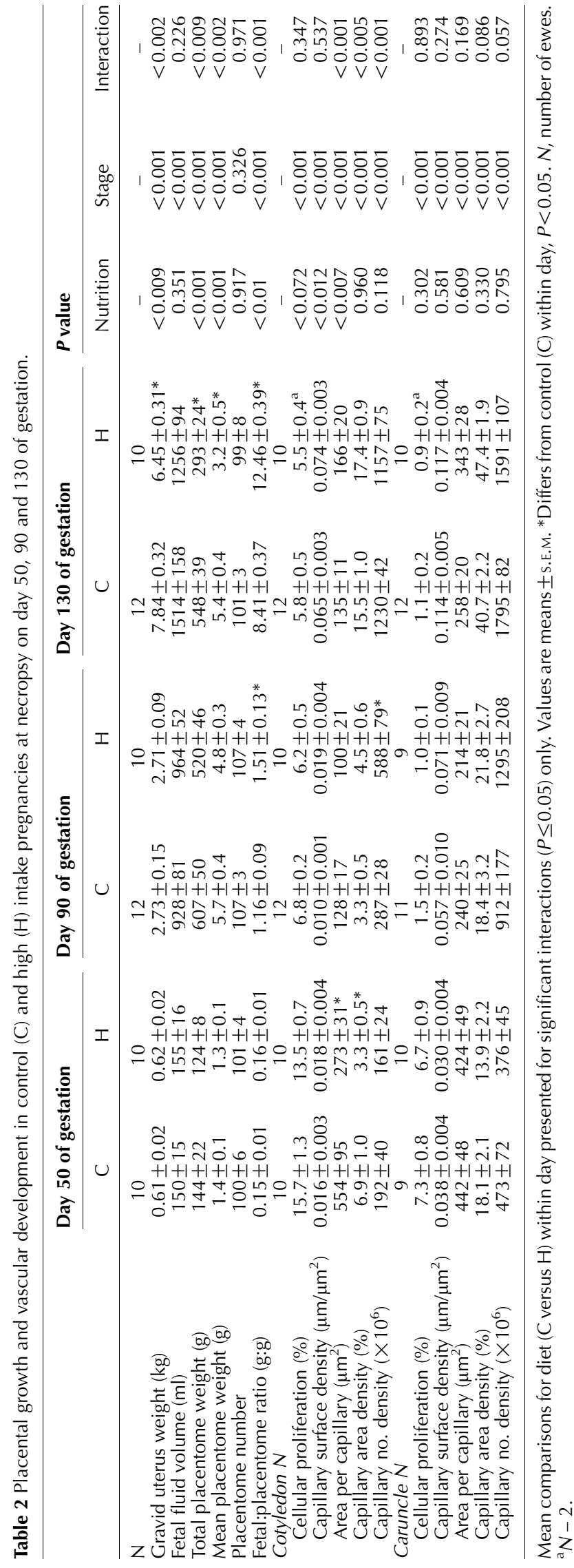

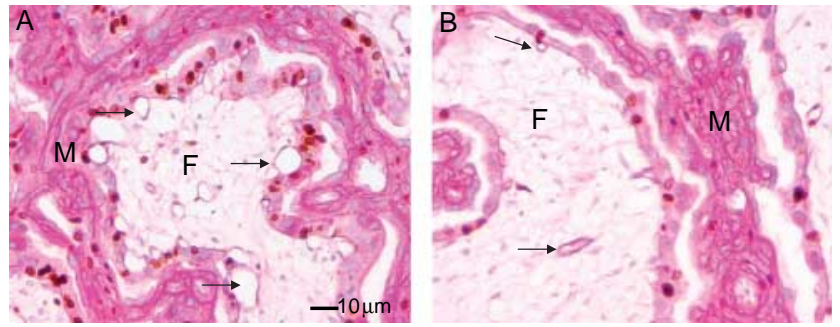

Figure 2 Representative micrographs of vascular perfused cotyledonary tissue at day 50 of gestation in control (A) and high (B) dietary-intake groups. The pinkish staining (periodic acid-Schiff's reagent) represents primarily basement membranes, including those of the microvessels (capillaries, arterioles, and venules; Borowicz et al. 2007), the brown nuclei indicate the presence of BrdU and therefore marks DNA synthesis and thus cell proliferation (Johnson et al. 1997a, 1997b, Reynolds et al. 1998), and the bluish nuclei represent non-proliferating nuclei counterstained stained with hematoxylin. Cotyledonary capillary area density (capillary area per unit of cotyledonary tissue) and number density (number of capillaries per unit of cotyledonary tissue) were reduced by 46 and $51 \%$ respectively in the high (B) versus the control (A) dietary groups at day 50 of gestation (Table 2). Arrows show examples of cotyledonary capillaries. Note the difference in both capillary size and number between panels $\mathrm{A}$ and $\mathrm{B}(\mathrm{C}$ versus $\mathrm{H}$ respectively). $M=$ maternal caruncular (dark pinkish), and $F=$ fetal cotyledonary (light pinkish) tissue areas. Bar (A) represents both panels $=10 \mu \mathrm{m}$.

\section{Discussion}

The design of the present study enabled cross-sectional assessment of fetoplacental growth at three key stages of gestation in a large cohort of adolescent animals where embryo donor genetics was controlled for at conception. This approach was critical to determine the basis of the previously observed changes in placental development and function in late gestation. The study demonstrated that placental mass per se is not perturbed by maternal overfeeding until sometime during the final third of pregnancy and as such confirms previous studies in which the pregnancies were terminated at single points coincident with either mid (Wallace et al. 2004b, Redmer et al. 2005) or late (Wallace et al. 2000, $2002 a, 2002 b, 2007)$ gestation. Moreover, the data revealed for the first time that the fetuses of overnourished dams may be initially on a higher growth trajectory than control fetuses between day 50 and 90 of gestation, with fetal weight being $11 \%$ greater by day 90 in the $\mathrm{H}$ group. Indeed, the greater fetal amniotic glucose at day 50 and the greater amniotic and fetal plasma glucose at day 90 are commensurate with the ready availability of nutrients in the maternal circulation of the overnourished dams.

Under normal conditions (i.e., normal placental growth and development), transport of glucose to the fetus is dependent on the maternal:fetal transplacental glucose concentration gradient (Bell et al. 1999), which is the physiological driving force that determines placental glucose uptake and transfer to the fetus 
(Simmons et al. 1979). In the present study, maternal glucose concentrations were elevated at all necropsy stages in the overnourished dams, and it was only during the last third of gestation, when the mass of the placenta was subsequently impaired, that the absolute nutrient transfer capacity of the placenta became limiting for further fetal growth (Wallace et al. 2002b). Consequently, by day 130 of gestation, fetal growth had slowed and fetal body weight was reduced by $20 \%$ in fetuses from overnourished dams compared with those from controls, coincident with a $40 \%$ reduction in placental mass. This switching between prenatal growth trajectories in response to a putative relative excess and then a gradual deficit of glucose supply (the main fetal fuel), may underlie previous observations that reported increased fetal weight-specific perirenal and carcass fat contents at late gestation in growth-restricted fetuses from overnourished dams (Matsuzaki et al. 2006).

The design of the present study also allowed us for the first time to assess early placental growth and vascular development in relation to maternal nutritional status. Although cellular proliferation within the fetal cotyledon was only marginally influenced by maternal diet at day 50 of gestation, we did observe a significant reduction in the vascular development within the fetal cotyledon at this early stage. The reductions in capillary area density and area per capillary (i.e., vessel size) in the overnourished dams may explain the previously reported reductions in uterine blood flow in mid-gestation (Wallace et al. 2008a) and in uteroplacental blood flows and nutrient uptakes in late gestation (Wallace et al. 2002a, 2002b, 2003a) in this experimental paradigm. The mechanism underlying this nutritionally-mediated alteration in vascular development is unknown. One possibility is that nutritionally induced suppression of the major sex steroids in the overnourished dams may be influencing both placental angiogenesis and vascular development. In this and earlier studies, we have shown that maternal progesterone concentrations are attenuated throughout gestation in overnourished dams (Wallace et al. 1997b, 2003a). We had insufficient plasma to evaluate maternal estrogen in the present study due to the requirement to extract the steroid from a large volume of plasma. However, we have recently shown that circulating oestradiol- $17 \beta$ concentrations in identically nutritionally manipulated overnourished dams fail to increase in parallel with those of control dams between day 50 and 75 of gestation (Wallace et al. 2008b). The reproductive steroids are strongly implicated in the control of uterine growth (Johnson et al. 1997a, 1997b, Reynolds et al. 1998), vascular development and function, and blood flow (Cullinan-Bove \& Koos 1993, Reynolds \& Redmer 2001, Reynolds et al. 2006). In addition, physiological doses of oestradiol upregulate expression of angiogenic factors in the uterine endometrium (Cullinan-Bove \& Koos 1993, Reynolds et al. 1998, Johnson et al. 2006), which provides a plausible route whereby nutrition may affect steroid levels and ultimately vascular architecture and function in the placenta.

Alternatively, nutritionally-mediated alterations in placental angiogenesis and vascular development may reflect differences in circulating somatotrophic hormones. Insulin and, to a lesser extent, IGF1 concentrations are elevated from early in gestation in overnourished dams and provide a sustained anabolic stimulus to maternal tissue deposition (Wallace et al. 1997 a, present study). The resulting progressive increase in adiposity may compromise blood flow to the gravid uterus and hence limit placental vascular development. Maternal cardiac output during pregnancy normally increases by $\sim 70 \%$ in the sheep, which results in a redistribution of the percentage of cardiac output going to the various organs, and particularly the gravid uterus (Rosenfeld 1977). Clearly, both cardiac output and the partitioning of blood to the maternal versus gravid uterine tissues may be influenced by the increasing adiposity of the dams, but this aspect has not yet been directly measured in the overnourished paradigm. Irrespective of the putative mechanism, the early perturbation in fetal rather than maternal placental vascular development in overnourished pregnancies is in line with previous observations of a relative delay in ovine placental lactogen secretion in this model (indicative of inadequate binucleate cell migration from the fetal trophectoderm; Lea et al. 2007) and with reduced proliferative activity within the fetal trophectoderm at the apex of placental growth (Lea et al. 2005).

However, the early reduction in fetal cotyledonary vascular development was not evident at mid-gestation (day 90). Indeed, at this stage, a twofold increase in capillary area density was observed in the fetal cotyledon of overnourished dams, whereas all other placental vascular parameters were independent of maternal nutrition. Although this contrasts with the observations at day 50, it may reflect a transient compensatory vascular response and an acceleration (or mismatch) of the normal pattern of placental vascular development at this stage, before the mass of the placenta per se is perturbed. However, notwithstanding these observations, serial assessments of uterine arterial blood flow in vivo reveal a $40 \%$ reduction at day 88 of gestation in overnourished compared with control dams (Wallace et al. 2008a). By late gestation, total placentome mass was reduced by $46 \%$ yet placental vascular morphology assessed by the techniques described herein was similar in both groups. This suggests that the major reductions in uterine and umbilical blood flows previously measured in late gestation (Wallace et al. 2002a, 2002b) may be more reflective of a total reduction in total placental vascular volume due to reduced placental size per se rather than reduced vascular volume per unit of placental tissue (as measured here). Indeed, when late gestation uterine 
blood flow is expressed on a placental weight-specific basis, it is equivalent in overnourished and control pregnancies (Wallace et al. 2002a, 2002b).

Although it can be argued that the morphometric methodologies used herein are limited by the 2-D nature of the image analyses, the changes in the patterns of vascular development throughout gestation are strikingly similar to those reported previously during normal pregnancy in adult ewes using identical procedures (Borowicz et al. 2007). Furthermore, both sets of data are similar to the observations of Stegeman (1974) both in pattern and magnitude of the increase in placental vascularization that she determined using a microscopic point counting method. Moreover, the increases in placentome capillary area density and in cotyledonary capillary number and surface density from early to late gestation are in broad agreement with previously documented cross-sectional measurements of changes in uterine (maternal) and umbilical (fetal) blood flows in vivo, measured at mid and late gestation (Rosenfeld et al. 1974, Molina et al. 1990).

In this study, we evaluated fetoplacental growth and vascular development at several critical stages of gestation using histology combined with sophisticated image analysis techniques. We determined that high maternal intake designed to promote rapid maternal growth influenced capillary development in the fetal portion of the placenta during early to mid-pregnancy, which may underlie the subsequent reduction in placental mass and hence fetal nutrient supply observed during the final third of gestation. These data will guide future studies designed to determine the mechanisms responsible for compromised placental development and function in overfed adolescents.

\section{Materials and Methods}

\section{Animals and experimental design}

All procedures were licensed under the UK Animals (Scientific Procedures) Act of 1986 and approved by the Rowett Institute's Ethical Review Committee.

Embryos from superovulated adult ewes (Border Leicester $\times$ Scottish Blackface), inseminated by a single sire, were recovered on day 4 after estrus and transferred synchronously in singleton into the uterus of recipient ewe lambs (Dorset Horn $\times$ Greyface), exactly as described previously (Wallace et al. 1997a). This protocol ensured that placental and fetal growth was not influenced by varying fetal number or partial embryo loss. In addition, the use of a single sire and a limited number of embryo donors maximized the homogeneity of the resulting fetuses. Donor ewes were multiparous, between 3 and 4 years of age, had a body weight of $72.9 \pm 2.32 \mathrm{~kg}$ and had a body condition score of $2.4 \pm 0.03$ units (evaluated on a scale of 0 to 5 , where $0=$ extremely emaciated and 5 $=$ extremely fat, according to the criteria of Russel et al. (1969)) at the time of embryo recovery. Embryo transfers were carried out in two batches of three and four consecutive days separated by a two-week period during the mid-breeding season of the same year. As far as possible, pregnancies resulting from each embryo transfer day were equally represented at each of the three gestational stages studied. All animals were housed in individual pens under natural lighting conditions.

At the time of embryo transfer, recipient ewe lambs were peripubertal ( $\sim 7.5$ months of age) and had a mean body weight of $43.7 \pm 0.39 \mathrm{~kg}$, body condition score of $2.3 \pm 0.01$ units, and ovulation rate of $2.1 \pm 0.15$. Based on these parameters, recipient ewe lambs were evenly allocated to receive a control $(\mathrm{C})$ or high $(\mathrm{H})$ quantity of the same complete diet. Care was also taken to randomize for the maternity of the embryo so that embryo donor genetics were equally represented in both groups at the outset of the study. The dietary level in the $\mathrm{C}$ group was calculated to maintain normal maternal adiposity throughout gestation (i.e., no change from initial starting adiposity) and hence meet the estimated metabolizable energy requirements for optimum conceptus growth and pregnancy outcome in this genotype (AFRC 1993). To achieve this objective, the moderate intake, $\mathrm{C}$ group, was fed to promote a modest maternal weight gain $(\sim 50 \mathrm{~g} /$ day $)$ during the first two thirds of gestation, followed by step-wise increases in maternal intake during the final third of gestation that were calculated to meet the increasing demands of the developing fetus. By contrast, the $\mathrm{H}$ or ad libitum intake group consumed equivalent to approximately twice the estimated metabolizable energy requirements, and this level of intake was calculated to promote rapid maternal growth. The complete diet supplied $12 \mathrm{MJ}$ of metabolizable energy and $140 \mathrm{~g}$ of crude protein per $\mathrm{kg}$ and was offered in two equal feedings at 0800 and $1600 \mathrm{~h}$ daily (see Wallace et al. 2006b for full details of the diet composition, analyses, and typical intakes for this nutritional paradigm).

Maternal body condition score was evaluated every two weeks by the same experienced assessor. Pregnancy status was determined by transabdominal ultrasonography at approximately day 45 of gestation (gestation length $\sim 145$ days). Pregnancy was established and maintained in 34 and 30 ewes in the $\mathrm{C}$ and $\mathrm{H}$ groups respectively. Pregnancies were terminated at day 50,90 or 130 of gestation ( $n=10$ to 12 pregnancies per treatment group at each day of gestation). At necropsy on day 50, one animal from the $\mathrm{H}$ group was diagnosed as having severe ruminitis, and maternal and fetal necropsy data collected from this ewe were excluded from further analysis.

\section{Blood sample collection and necropsy procedures}

Before necropsy on day 50, 90 or 130 of gestation, a catheter was inserted into the maternal jugular vein and a blood sample was collected. Exactly $1 \mathrm{~h}$ before euthanasia, to determine the relative rate of placental cell proliferation (the labeling index), the dams were infused with 5-bromo-2'-deoxyuridine (BrDU, $5 \mathrm{mg} / \mathrm{kg}$ of body weight, dissolved in phosphate buffered saline (PBS) to form a saturated solution of $16.7 \mathrm{mg}$ of $\mathrm{BrdU} / \mathrm{ml}, \mathrm{pH}$ 7.0), as we have previously described (Jablonka-Shariff et al. 1993). Euthanasia was achieved by i.v. administration of an overdose of sodium pentobarbitone (20 ml Euthesate; $200 \mathrm{mg}$ 
pentobarbitone/ml; Willows Francis Veterinary, Crawley, UK) and exsanguination (by severing the main vessels of the neck). The gravid uterus was removed, weighed, and opened, and a sample of amniotic fluid was rapidly obtained for subsequent glucose analyses. At day 90 or 130 of gestation all fetal hearts were clearly and strongly beating when the uterus was opened and a blood sample was collected by cardiac puncture immediately before intracardiac administration of sodium pentobarbitone ( $3 \mathrm{ml}$ Euthesate) to kill the fetus. After clamping the umbilical cord, the fetus was removed, dried, weighed, and its component organs were dissected. The maternal liver, pancreas, and perirenal fat were also dissected and weighed.

Maternal and fetal plasma and amniotic glucose concentrations at necropsy were determined in duplicate using a Yellow Springs Instruments (YSI, Yellow Springs, OH, USA) dual biochemistry analyzer (model 2700), as previously described (Wallace et al. 2002a). Variation between duplicates was $<5 \%$ in all cases. Maternal progesterone, and maternal and fetal insulin and IGF1 concentrations were measured in duplicate by RIA, as described previously (Ronayne \& Hynes 1990, Bruce et al. 1991, MacRae et al. 1991). The sensitivities of the assays were $0.2 \mathrm{ng}$ progesterone $/ \mathrm{ml}, 4 \mu \mathrm{U}$ insulin $/ \mathrm{ml}$, and $6 \rho \mathrm{mol}$ IGF1/ml. The concentration of each hormone was measured within a single assay and the intraassay coefficients of variations were $<10 \%$.

\section{Quantification of placental cellular proliferation and vascularity}

Two representative placentomes from the gravid uterine horn were sliced into $7 \mathrm{~mm}$ cross sections and were immersion fixed in Carnoy's fixative for $6 \mathrm{~h}$, followed by $70 \%$ ethanol, which changed once after $24 \mathrm{~h}$ (for BrDU immunohistochemistry).

Maternal caruncular and fetal cotyledonary tissues of the placenta were perfused after catheterizing branches of the uterine and umbilical arteries respectively, as previously described (Borowicz et al. 2007). Briefly, a catheter was inserted into the artery, secured with suture and perfused in the following sequence: 1) $10 \mathrm{ml} \mathrm{PBS}$; 2) $5 \mathrm{ml}$ or less of Evans Blue dye to check perfusion; 3) $10 \mathrm{ml}$ PBS; 4) $10 \mathrm{ml}$ Carnoy's solution; 5) $10 \mathrm{ml} \mathrm{PBS}$ and 6) $10.8 \mathrm{ml}$ of a Mercox resin vascular casting mixture (Ladd Research Industries, Inc., Burlington, Vermont, USA). Perfused placentomes were then removed from the uterus, weighed, sliced into $7 \mathrm{~mm}$ cross sections and immersed in Carnoy's fixative. All remaining placentomes were dissected and weighed.

To evaluate cellular proliferation and vascularity, Mercoxperfused placentome tissues (one sample each from maternal caruncular and fetal cotyledon perfusions) were embedded in paraffin, sectioned $(5 \mu \mathrm{m})$ and then were incubated with a monoclonal antibody to $\mathrm{BrDU}$ (a thymidine analog; $100 \mu \mathrm{g} / \mathrm{ml}$; Roche Diagnostics Ltd) or normal mouse IgG ( $2 \mu \mathrm{g} / \mathrm{ml}$, negative control), followed by the previously described staining method for determination of vascularity (Reynolds et al. 1992). Thereafter, placentome vascularity and cellular proliferation were quantified according to the methods of Borowicz et al. (2007). Briefly, the slides were visualized with a Leica DMR microscope (Leica
Microsystems, Welzlar, Germany) at $20 \times$ magnification and 10 digital images of well-perfused regions were captured with a Hamamatsu camera (C5810, Leica Microsystems) and analyzed using Image-Pro Plus, version 4.5.1 software (Media Cybernetics, Inc., Silver Spring, MD, USA). The number of BrDU-labeled nuclei was counted and divided by the total number of nuclei in the maternal caruncular or fetal cotyledonary tissue. Figure 2 shows placentome vascularity and BrDU staining. Total caruncular area $\left(\mu \mathrm{m}^{2}\right)$ and shrinkage area $\left(\mu \mathrm{m}^{2}\right)$ were determined, and each caruncular or cotyledonary capillary was individually traced to quantify the total vessel area $\left(\mu \mathrm{m}^{2}\right)$, number, and perimeter $(\mu \mathrm{m})$ per each tissue area. Shrinkage was determined by tracing all areas of shrink space (visual artifactual separation of tissue areas seen in most sections) within an image and subtracting from the total tissue areas as shown below. Based on these measurements, total cotyledonary area $\left(\mu \mathrm{m}^{2}\right.$; total tissue area - (caruncular area + shrinkage area)), capillary area density (\%; capillary area/tissue area), capillary number density (number of capillaries per $\mathrm{mm}^{2}$; capillary number/ tissue area), capillary surface density (capillary perimeter/ tissue area), area per capillary $\left(\mu \mathrm{m}^{2}\right.$; capillary area/capillary number), and perimeter per capillary $(\mu \mathrm{m}$; capillary perimeter/capillary number) were calculated for each perfused cotyledon and caruncle image.

\section{Statistical analysis}

Data are presented as means \pm S.E.M. Differences between nutritional treatments for maternal and fetal blood parameters and organ weights from each of days 50,90 or 130 of gestation were analyzed by one-way ANOVA (General Linear Models, Minitab, State College, PA, USA). A similar approach was used to analyze body weight and body condition score collected throughout gestation after calculating a mean individual value spanning the first (from day 4 to day 49), second (from day 50 to day 90), and final third of gestation (day 91 to day 130). Uteroplacental mass and placental vascularity data from days 50, 90, and 130 of gestation were analyzed by two-way ANOVA (PROC GLM procedure of SAS; SAS Inst. Inc., Cary, NC, USA) to determine the main effects of nutrition and day of gestation and the interaction between nutrition and day of gestation. In specified instances, these latter parameters were also analyzed by one-way ANOVA within a day of gestation. When the nutrition $\times$ day of gestation interaction was significant $(P<0.05)$, means were separated by orthogonal contrasts of the least squares means. Main effects were considered significant when $P<0.05$.

\section{Declaration of interest}

The authors declare that there is no conflict of interest that could be perceived as prejudicing the impartiality of the research reported.

\section{Funding}

Funded by the Scottish Government (RERAD Workpackage 4.2) and the National Institutes of Health (grants HL64141 and HD45784), USA. 


\section{Acknowledgements}

The authors gratefully acknowledge Masatoshi Matsuzaki of Hirosaki University, Hirosaki, Japan for assistance during animal necropsy and Corrie Redmer of North Dakota State University, Fargo, ND, USA for assisting with the placental vascularity analysis.

\section{References}

AFRC 1993 Energy and Protein Requirements of Ruminants. An Advisory Manual Prepared by the AFRC Technical Committee on Responses to Nutrients, Wallingford, UK: CAB International.

Bell AW, Wilkening RB \& Meschia G 1987 Some aspects of placental function in chronically heat-stressed ewes. Journal of Developmental Physiology 9 17-29.

Bell AW, Hay WW Jr \& Ehrhardt RA 1999 Placental transport of nutrients and its implications for fetal growth. Journal of Reproduction and Fertility 54 401-410.

Borowicz PP, Arnold DR, Johnson ML, Grazul-Bilska AT, Redmer DA \& Reynolds LP 2007 Placental growth throughout the last two-thirds of pregnancy in sheep: vascular development and angiogenic factor expression. Biology of Reproduction 76 259-267.

Bruce LA, Atkinson T, Hutchinson JSM, Shakespear RA \& MacRae JC 1991 The measurement of insulin-like growth factor I in sheep plasma. Journal of Endocrinology 128 R1-R4.

Cullinan-Bove K \& Koos RD 1993 Vascular endothelial growth factor/vascular permeability factor expression in the rat uterus: rapid stimulation by estrogen correlates with estrogen-induced increases in uterine capillary permeability and growth. Endocrinology 133 829-837.

Ehrhardt RA \& Bell AW 1995 Growth and metabolism of the ovine placenta during mid-gestation. Placenta 16 727-741.

Jablonka-Shariff A, Grazul-Bilska AT, Redmer DA \& Reynolds LP 1993 Growth and cellular proliferation of ovine corpora lutea throughout the estrous cycle. Endocrinology 133 1871-1879.

Johnson ML, Redmer DA \& Reynolds LP 1997a Effects of ovarian steroids on uterine growth, morphology, and cell proliferation in ovariectomized, steroid-treated ewes. Biology of Reproduction 57 588-596.

Johnson ML, Redmer DA \& Reynolds LP 1997b Uterine growth, cell proliferation, and c-fos proto-oncogene expression throughout the estrous cycle in ewes. Biology of Reproduction 56 393-401.

Johnson ML, Grazul-Bilska AT, Redmer DA \& Reynolds LP 2006 Effects of estradiol-17beta on expression of mRNA for seven angiogenic factors and their receptors in the endometrium of ovariectomized (OVX) ewes. Endocrine 30 333-342.

Lea RG, Hannah LT, Redmer DA, Aitken RP, Milne JS, Fowler PA, Murray JF \& Wallace JM 2005 Developmental indices of nutritionally induced placental growth restriction in the adolescent sheep. Pediatric Research 57 599-604.

Lea RG, Wooding P, Stewart I, Hannah LT, Morton S, Wallace K, Aitken RP, Milne JS, Regnault TR, Anthony RV et al. 2007 The expression of ovine placental lactogen, StAR and progesterone-associated steroidogenic enzymes in placentae of overnourished growing adolescent ewes. Reproduction 133 785-796.

MacRae JC, Bruce LA, Hovell B, Hart IC, Inkster J \& Atkinson T 1991 Influence of protein nutrition on the response of growing lambs to exogenous bovine growth hormone. Journal of Endocrinology 130 53-61.

Matsuzaki M, Milne JS, Aitken RP \& Wallace JM 2006 Overnourishing pregnant adolescent ewes preserves perirenal fat deposition in their growth-restricted fetuses. Reproduction, Fertility, and Development 18 357-364.

Molina RD, Meschia G \& Wilkening RB 1990 Uterine blood flow, oxygen and glucose uptakes at mid-gestation in the sheep. Proceedings of the Society for Experimental Biology and Medicine 195 379-385.

Olausson PO, Cnattingius S \& Haglund B 1999 Teenage pregnancies and risk of late fetal death and infant mortality. British Journal of Obstetrics and Gynaecology 106 116-121.
Redmer DA, Aitken RP, Milne JS, Reynolds LP \& Wallace JM 2005 Influence of maternal nutrition on messenger RNA expression of placental angiogenic factors and their receptors at midgestation in adolescent sheep. Biology of Reproduction 72 1004-1009.

Reynolds LP \& Redmer DA 1995 Utero-placental vascular development and placental function. Journal of Animal Science 73 1839-1851.

Reynolds LP \& Redmer DA 2001 Angiogenesis in the placenta. Biology of Reproduction 64 1033-1040.

Reynolds LP, Killilea SD \& Redmer DA 1992 Angiogenesis in the female reproductive system. FASEB Journal 6 886-892.

Reynolds LP, Kirsch JD, Kraft KC, Knutson DL, McClaflin WJ \& Redmer DA 1998 Time-course of the uterine response to estradiol- $17 \beta$ in ovariectomized ewes: uterine growth and microvascular development. Biology of Reproduction 59 606-612.

Reynolds LP, Borowicz PP, Vonnahme KA, Johnson ML, Grazul-Bilska AT, Wallace JM, Caton JS \& Redmer DA 2005 Animal models of placental angiogenesis. Placenta 26 689-708.

Reynolds LP, Caton JS, Redmer DA, Grazul-Bilska AT, Vonnahme KA, Borowicz PP, Luther JS, Wallace JM, Wu G \& Spencer TE 2006 Topical review: evidence for altered placental blood flow and vascularity in compromised pregnancies. Journal of Physiology 572 51-58.

Ronayne E \& Hynes N 1990 Measurement of plasma progesterone concentrations by extraction and non-extraction radioimmunoassay. Irish Journal of Agricultural Research 29 109-115.

Rosenfeld CR 1977 Distribution of cardiac output in ovine pregnancy. American Journal of Physiology $232 \mathrm{H} 231-\mathrm{H} 235$.

Rosenfeld CR, Morriss FH Jr, Makowski EL, Meschia G \& Battaglia FC 1974 Circulatory changes in the reproductive tissues of ewes during pregnancy. Gynecologic Investigation 5 252-268.

Russel AJF, Doney JM \& Gunn RG 1969 Subjective assessment of body fat in live sheep. Journal of Agricultural Science 72 451-454.

Scholl TO, Hediger ML, Schall JI, Khoo CS \& Fischer RL 1994 Maternal growth during pregnancy and the competition for nutrients. American Journal of Clinical Nutrition 60 183-201.

Scholl TO, Hediger ML \& Schall JI 1997 Maternal growth and fetal growth: pregnancy course and outcome in the Camden study. Annals of the New York Academy of Sciences 81 292-301.

Simmons MA, Battaglia FC \& Meschia G 1979 Placental transfer of glucose. Journal of Developmental Physiology 1 227-243.

Stegeman JHJ 1974 Placental development in the sheep and its relation to fetal development. Bijdragen Tot de Dierkunde 44 3-72.

Wallace JM, Aitken RP \& Cheyne MA 1996 Nutrient partitioning and fetal growth in rapidly growing adolescent ewes. Journal of Reproduction and Fertility 107 183-190.

Wallace JM, Da Silva P, Aitken RP \& Cheyne MA 1997 a Maternal endocrine status in relation to pregnancy outcome in rapidly growing adolescent sheep. Journal of Endocrinology 155 359-368.

Wallace JM, Aitken RP, Cheyne MA \& Humblot P $1997 b$ Pregnancy specific protein $\mathrm{B}$ and progesterone concentrations in relation to nutritional regimen, placental mass and pregnancy outcome in growing adolescent ewes carrying singleton fetuses. Journal of Reproduction and Fertility 109 53-58.

Wallace JM, Bourke DA, Aitken RP, Palmer RM, Da Silva P \& Cruickshank MA 2000 Relationship between nutritionally-mediated placental growth restriction and fetal growth, body composition and endocrine status during late gestation in adolescent sheep. Placenta 21 100-108.

Wallace JM, Bourke DA, Da Silva P \& Aitken RP 2001 Nutrient partitioning during adolescent pregnancy. Reproduction 122 347-357.

Wallace JM, Bourke DA, Aitken RP, Leitch N \& Hay WW Jr 2002a Blood flows and nutrient uptakes in growth-restricted pregnancies induced by overnourishing adolescent sheep. American Journal of Physiology. Regulatory, Integrative and Comparative Physiology 282 R1027-R1036.

Wallace JM, Bourke DA, Aitken RP, Milne RA, Milne JS \& Hay WW Jr $2002 b$ Placental glucose transport in growth-restricted pregnancies induced by overnourishing adolescent sheep. Journal of Physiology 547 85-94.

Wallace JM, Bourke DA, Da Silva P \& Aitken RP 2003a Influence of progesterone supplementation during the first third of pregnancy on fetal and placental growth in overnourished adolescent ewes. Reproduction 126 481-487. 
Wallace JM, Aitken RP, Buchan V \& Hay WW Jr 2003 b Amino acid fluxes in growth-restricted pregnancies induced by overnourishing adolescent sheep. Placenta 24 A9.

Wallace JM, Aitken RP, Milne JS \& Hay WW Jr 2004a Nutritionally-mediated placental growth restriction in the growing adolescent: consequences for the fetus. Biology of Reproduction 70 1055-1062.

Wallace JM, Milne JS \& Aitken RP 2004b Maternal growth hormone treatment from Day 35 to 80 of gestation alters nutrient partitioning in favor of uteroplacental growth in the overnourished adolescent sheep. Biology of Reproduction 70 1277-1285.

Wallace JM, Luther JS, Milne JS, Aitken RP, Redmer DA, Reynolds LP \& Hay WW Jr 2006a Nutritional modulation of adolescent pregnancy outcome - a review. Placenta 27 S61-S68.

Wallace JM, Milne JS, Redmer DA \& Aitken RP $2006 b$ Effect of diet composition on pregnancy outcome in overnourished rapidly growing adolescent sheep. British Journal of Nutrition 96 1060-1068.
Wallace JM, Milne JS, Aitken RP \& Hay WW Jr 2007 Sensitivity to metabolic signals in late gestation growth restricted fetuses from rapidly growing adolescent sheep. American Journal of Physiology. Endocrinology and Metabolism 293 E1233-E1241.

Wallace JM, Milne JS, Matsuzaki M \& Aitken RP 2008a Attenuated uterine blood flow is an early defect in growth-restricted pregnancies induced by overnourishing adolescent dams. Placenta 29 718-724.

Wallace JM, Milne JS, Aitken RP, Reynolds LP \& Redmer DA $2008 b$ Putative role for oestrogen as the missing link between nutrition and feto- placental growth restriction in overnourished adolescent sheep. Proceedings of the Physiological Society 11 PC37.

Received 12 December 2008

First decision 6 January 2009

Accepted 22 January 2009 